THE INTERNATIONAL

REVIEW OF RESEARCH IN

OPEN AND DISTANCE LEARNING

\title{
An Investigation of Communication in Virtual High Schools
}

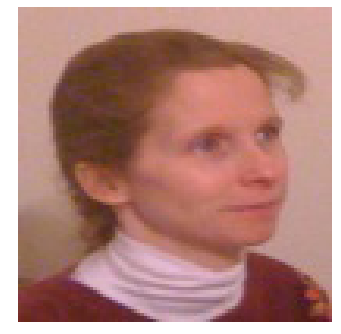

Marley Belair

\section{Abstract}

Virtual schooling is an increasing trend for secondary education. Research of the communication practices in virtual schools has provided a myriad of suggestions for virtual school policies. The purpose of this qualitative study was to investigate the activities and processes involved in the daily rituals of virtual school teachers and learners with the goal of determining how regular phone calls by teachers contributed to the work habits of students. Eight virtual teachers were observed attempting to contact more than 60 struggling learners. Phone conversations with 12 of these learners showed that teachers repeatedly attempted to help them. Eleven students were interviewed and indicated preferences for written communications. Ten additional teachers who were interviewed emphasized the difficulty they had in reaching students by phone and the lack of student responses to phone-call attempts. The teachers in the study provided additional data regarding their regular communication patterns. Archival records from more than 100 contact attempts showed that approximately $20 \%$ of the students responded to teacher phone calls and less than half of these students completed the work requested. The interview data revealed that teachers believe written communications or multiple forms of communication may be more effective than regular phone calls. Future research should extend current research by expanding on sample size and investigating alternate methods of communication. Further investigation of learner responses to phone calls and of nonresponsive students could add to this data.

Keywords: Distance education; virtual school, communication

\section{Introduction}

Virtual schools have begun to overtake other forms of charter schools in many of the states in which charters are permitted (Kanna, Gillis, \& Culver, 2009; Peterson, 2010). The last decade has seen a plethora of virtual schools, from those that are state chartered to those 
run by management corporations, offering individual courses, credit recovery, and full high-school diplomas (Barbour \& Reeves, 2009). Research has shown that teacher practices and policies play the most important roles in student success in virtual schools (Oliver, Osborne, \& Brady, 2009; Weiner, 2003).

Teacher communications may be vital factors for virtual school success (Dennen, Darabi, \& Smith, 2007; Greenway \& Vanourek, 2006; Oliver et al., 2009; Weiner, 2003). The history of virtual schooling and virtual school studies are important facets for understanding virtual school communications. In order to understand the best practices for communication, qualitative analysis must be used to evaluate the nature of a variety of communication practices. The establishment of best practices for virtual communications is essential due to the rapid growth of virtual programs (Watson, 2007). Without uniform standards for communications and other aspects of educational effectiveness, virtual schools will not be able to conform to the expectations that parents and school administrators have established (Ferdig, Cavanaugh, DiPietro, Black, \& Dawson, 2009; U.S. Department of Education, 2008). The dearth of reliable qualitative data for assessing the effectiveness of virtual school communications could become a threat to the significance of the virtual school movement as a whole (Watson, 2007). There is limited research investigating online virtual K-12 school practices (Means, Toyama, Murphy, Bakia, \& Jones, 2009).

Research on communication practices and transactional distance is important for evaluating virtual school programs (Moore \& Kearsley, 1996). Communication is just one facet of transactional distance. However, any program in which the major forms of communication must be carried out through electronic media generally involves a higher degree of transactional distance (Moore, 2007). The degree and effectiveness of the various communication practices for a given program also affect the level of transactional distance (Anderson, 2007; Saba, 2007). Virtual schools must use effective communications to decrease the transactional distance and to ensure that participants do not feel constrained by differences in location (Lowry, Roberts, Romano, Cheney, \& Hightower, 2006). The results of some studies have indicated that the form of communication is less important than the personal factors involved in ensuring successful communication practices in virtual schooling (Harms, Niederhauser, Davis, Roblyer, \& Gilbert, 2006; Means et al., 2009).

The theory of transactional distance has been updated, tested, and reworked since it was first established (Moore, 2007). One premise for the continual investigation into the theory is that effective virtual school research requires investigating policies and practices from previous studies (Saba, 2007). This research was aligned with the review of recent literature on virtual school and communication studies. A qualitative approach for evaluating the communication practices for various schools was important because comprehensive, qualitative data lends itself to informing a cohesive picture of the school practices (Armstrong, 2006). The results of communications between students and teachers in this study were evaluated through the observations and interviews of participants within several virtual schools. It has been suggested that teacher and student interactions should be measured in qualitative ways to obtain a true representation of the effectiveness of the communications (Moore \& Kearsley, 1996; Shearer, 2007). 


\section{Method}

The research methods involved observations, interviews, and investigation of archival data from four virtual schools in North America. Personal observations and one-on-one interviews were vital in order to evaluate the methods of communication within the virtual school systems and to understand how the participants experience the system itself (Moustakas, 1994). Eight teachers were observed in their natural school environments and provided personal perceptions through follow-up interviews in order to shed light on various aspects of their communications with students within the virtual school. Although student observation was not possible, 11 students were interviewed. Further interviews with teachers who were not associated with field observations served to substantiate the research data. A total of 18 teachers and 11 students were interviewed in order to provide a wealth of qualitative data.

\section{Participants}

Participants included 18 teachers and 11 students from select virtual schools in North America. The teacher participants for observations included eight teachers from two different Midwestern virtual schools. There were also five teachers from these schools, two teachers from the largest virtual state charter school in the Southwestern United States, two teachers from another Midwestern virtual school, and one from a private virtual school who participated in interviews. A range of teaching experience and education was represented by these teachers. Demographics about age, nationality, and teaching experience were not specifically noted for these participants unless the data was forthcoming because the goal of the study was to focus on communications. This sample size was appropriate for a qualitative study because the general nature of qualitative research is to examine a small sample in order to explore an idea or phenomenon in detail (Patton, 2002; Shank, 2006).

\section{Procedures}

This qualitative investigation used a nested case-study approach to determine how daily phone calls by teachers influenced students and contributed to the work habits of learners involved in four virtual high schools. The nested case-study format included observations of eight virtual school teachers in the natural surroundings of their daily school practices, combined with interviews of teachers and learners and follow-up data (Patton, 2002). Teacher observations were vital to this study because communication can only be evaluated within the natural surroundings of the participants in order to investigate the normal practices of the individuals (Harms et al., 2006). Interviews were also used to obtain inferences and perceptions from teachers and students involved in virtual schools (Yin, 2009). This combination of teacher observations and participant interviews within a case-study design allowed investigation of the personal components of teacher and student communications (Patton, 2002). Archival data such as written communications, student submissions, phone logs, and teacher notes was provided by 10 of the 18 teacher participants. The teacher observations, participant interviews, and archival data created a triangulation of sources to strengthen the study evidence (Patton, 2002; Yin, 2011). 
The naturalistic inquiry and field-study observations involved eight virtual school teachers. These teachers were observed while they attempted to contact students by phone. All phone conversations, teacher notes, and messages left during more than 60 contact attempts during these observation periods were recorded as direct study data. These teachers were also interviewed after the observation periods. Interview-only data included 10 other teachers and 11 students directly involved in four online schools in North America. The teachers and students were interviewed in order to provide substantiation to the observation data. These interviews proceeded according to the protocol provided in the appendixes. The individuals were asked directly about their personal communications within their virtual school environments. The teachers also provided archival data such as phone logs and the results of attempted communications to further triangulate the data provided through observations and interviews.

Although this was a qualitative study, an additional note-taker was suggested by the sponsoring organization in order to add credibility to the data. Having a note-taker was also important because the teachers and students within the study worked from their homes, and ethical concerns were more easily addressed through this procedure. The notes were compared in order to ensure that the true observations and substance of each interview or observation period were presented as accurate data.

The initial field observations included a pilot study with the investigation of a teacher with whom the researcher has worked previously in order to overcome researcher-presence obstacles that could prevent accurate data collection. These notes were analyzed for possible patterns and ideas for subsequent observations. Notes taken during this data collection included direct quotes from voice messages or conversations and the results or summaries of the communications, along with any notes the teacher may have made about the communications. This initial observation was considered a pilot case and allowed the researcher to determine that the study should proceed to the formal observation stage (Yin, 1984). In order to follow the exact structure of the research data, the observed teacher was asked to recommend a student for a pilot interview. This student was one with whom the observed teacher had communicated and the researcher had previously established a professional relationship (Johnson, 2001; Wengraf, 2001). These criteria were important for ensuring the success of the interview as a pilot for subsequent student interviews. Upon completion of the pilot study, it was determined that a laptop computer was the least intrusive way of taking notes since most participants were accustomed to this process. The data from the pilot observation and interviews was analyzed in order to determine the efficacy of the next step of the research.

After the initial review and comparison of the pilot study, field observations with eight other teachers commenced once the observation and interview protocol were established. During this time, four teachers who were recommended by the school administrators and who had agreed to participate were observed for approximately two hours each. During each observation, the researcher and note-taker recorded the communication factors and made notes about any follow-up that was needed to obtain student work samples or questions that needed addressed. The notes included records of all the actions made by each 
teacher, including direct quotes from each phone conversation or phone message. An interview followed each observation in order to obtain teacher perceptions and recommendations. These open-ended interviews used a notes template, which was the interview guide that was piloted with the original participant and which is included in Appendix A. Each participant was asked to fill in gaps in the notes or to respond to inquiries from the researcher during the follow-up interview. These interviews served to clarify any issues from the observations and allowed the researcher to glean the participants' perspectives on the observed events (Yin, 2011). The participants were also asked to recommend students for subsequent interviews described in this article. This method of snowball sampling helped to ensure that the students who were interviewed had been previously contacted by the teachers during the observations.

This phase continued with a similar pattern of alternating observations of four additional teachers and interviews with three students in order to build on previously collected data (Merriam \& Associates, 2002). Two of these observations occurred via webcam. One benefit of the teacher observation periods is that they were scheduled for times when teachers were planning to perform specific communication duties. Each teacher was asked to schedule the observation for a period of two hours in which they would normally make routine phone calls to students. Notes were taken for all observed communications with students. These communications were often in the form of voice messages and follow-up K-mails. (Kmails are the closed and internal communications used by many schools as alternatives to e-mails.) Verbal and nonverbal observations were also noted for each communication incident. Detailed field notes included direct quotes, communication summaries, and observer perceptions of the communication processes that transpired. Supporting documentation, such as student submissions or records of previous teacher communications and attempts, were obtained during the observation period or noted for the researcher to acquire at a later time. Many teachers provided background about each call during the observation periods. The researcher notes included detailed information about any follow-up documentation that needed to be obtained to substantiate the observations (Patton, 2002).

The researcher was able to interview only 5 of the 12 students with whom the observed teachers had communicated. These interviews were linked to the observation data because the knowledge gained from each interview was contextual (Kvale \& Brinkmann, 2009). Therefore, the interviews that aligned with previous observations may have provided a more accurate picture of virtual school communication practices than the observation alone. It was important to perform these interviews as soon as possible after the teacher observation to keep the information clear and relevant (Yin, 2011). The researcher asked students to reflect on the recent communications they had had with their teachers. This open-ended approach allowed the students to express personal beliefs that were not influenced by researcher promptings (Yin, 2011). Four out of five of these students cited the communication incident that was witnessed by the researcher in response to this question. These interview responses helped to provide triangulation by giving another perspective in order to represent the students' perceptions of the communication experiences (Johnson, 2001). These perceptions also provided a more accurate analysis of the transaction distance 
within these communication incidents.

It was important to compare the interview responses from the teachers who were observed and the students with whom they communicated. Teacher interviews that followed field observations each began with open-ended invitations for the teachers to comment on the activities of the observation periods. The supporting questions included asking the teachers to provide advice for effective phone communications with virtual students. Teachers were asked to explain their expectations for student participation in and responses to phone calls. Teachers were also asked to explain their rationale for phone-call selections. Students were asked to reflect on their expectations for teacher-initiated communications. They were also asked to reflect on their perceptions of specific phone calls that had recently been initiated by their teachers. All interviews concluded with the researcher summarizing the main points of the interview and asking the participants to verify these summaries (Kvale, 2007). The notes from these interviews included a series of direct quotes and note-taker observations written or typed directly on the interview guides as found in the appendixes. Some interview participants also provided documents to support the data from the interview. For example, one teacher showed her Dropbox entries for two students who had resubmitted the same work after teacher communications. Another teacher shared and explained her communication notes from the entire semester. The researcher summarized these documents in the interview notes or obtained electronic copies of the items when it was feasible. These documents also included records of previous communications or results of written communications and student submissions.

The interviews that were not linked to previous observations were conducted in a similar manner as outlined above. Interviews with 10 additional teachers and 6 students who were not involved in teacher observations provided additional perspectives about virtual school communications. Perspectives from the personal observations of people who could not participate in researcher observations due to privacy issues, geographical distance, or concern for human subjects helped to strengthen the triangulation of data. The researcher relied heavily on direct quotes and interview shells that provided initial interview questions and necessary background information for the participants to ensure effective data for these interviews.

The researcher began each interview by asking participants to reflect on recent phone-call communications and the roles these may have had in their virtual schooling practices. The participants were then asked to give and explain their beliefs about the importance of regular phone communication between students and teachers in the virtual school. The presentation of these questions varied based on the subject, as seen in the interview guides found in the appendixes, and helped to establish the communication patterns that emerged within the various virtual school platforms. Participants were also asked if they had specific examples they were willing to share regarding the effects of communication on student work habits. Follow-up or probing questions required listening to and analyzing the participants' initial answers in order to ascertain the best direction for each interview (Kvale \& Brinkmann, 2009). Participants were asked to substantiate their responses with school records or documents. Three teachers provided detailed documentation of communication 
attempts. This data helped generalize about the results of phone calls and written communications within virtual schools.

The analysis of the data included correlating the observation, interview, and archival data. The observation data was analyzed and coded for patterns such as repeating themes, words, or word fragments. Repeating phrases or condensed meanings within the direct quotes of teacher phone calls made during the eight observation periods were noted and tracked for 47 voice messages, 11 conversations with learning coaches, and conversations with 12 students. Procedures that may have reflected the reason for communications or the results of communications were also analyzed for patterns and noted. The data for interviews was analyzed using inductive analysis and a continuation of the coding scheme for direct quotes and condensed meanings.

\section{Results}

The teacher observations revealed similarities in communication styles. Every observed teacher started the observation period by looking through his or her grade book. Six of the eight teachers who were observed sent written communications to most of the students with whom they communicated or attempted contact. All eight teachers consulted previous notes of some form and contacted only those students who were not passing the course. Three of the teachers spoke with students and explained how to earn enough points to pass an assignment or the course. Communication practices such as increased volume or the use of repetition for emphasis were noted for at least two teachers. The results of these observations included details and direct quotes from 47 voice messages, 11 conversations with learning coaches, and interactions with 12 students. Interviews with five of the students with whom the observed teachers communicated provided secondhand evidence and another perspective to enrich the study data for these communication instances (Gubrium \& Holstein, 2001; Yin, 2011).

\section{Teacher Interviews}

A total of 10 teachers were interviewed over a three-week period. The teacher interviews varied in length from less than 30 minutes to more than 75 minutes. All but two teacher interviews began with the teachers sharing specific positive stories regarding recent communications with students. One teacher did not feel that he had experienced a recent enough conversation to comment on the first interview question. Another teacher summarized the various forms and reasons for her communications. All 10 of the teachers agreed that the rationale for phone calls was to reach students who would be able to pass by completing work in response to the phone call. Four teachers referred to a "bubble" as the demarcation line between failing and being able to pull up grades through intervention. It was important to note that the expectations for teacher communications may have varied for these interview participants because they represented four different virtual schools.

The 10 stand-alone teacher interviews and the 8 teacher interviews that followed observations were coded and categorized separately but the data was analyzed together. These 
teacher interview responses were copied and coded with a coding scheme similar to the observation coding described above. Inductive analysis was used to begin to code data as the interviews progressed and to add new categories as necessary (Neuendorf, 2002). The interviews were also analyzed with specific coding to distinguish direct quotes and condensed meanings (Kvale, 2007). The categories were related to the interview questions.

The direct quotes that were used for coding included the terms (a) prioritize, (b) make it personal, (c) communication is key, (d) immediate feedback, and (e) students do not return calls. The condensed meanings were used across several answers. These included (f) prefer written communication, (g) be yourself, (h) autonomy, (i) grades/percentages, (j) multiple/alternate forms of communication, (k) show concern, and (l) do not expect response. Frequency totals for the codes from teacher interviews are included in Table 1. The category for preferred written communications was used for teachers who responded that they or their students preferred e-mails or K-mails, or who used the words written communications. This code was marked 24 times in the data for all 18 interviews. There were 15 responses that included the fact that students do not return phone calls. Prioritize was used in response to several interview questions and appeared as a direct quote 13 times across 9 different interviews.

All of the teachers were asked what advice regarding communications they would give to a fellow virtual teacher. Of the 18 teachers, 7 responded that teachers should personalize their communication attempts and let the students know they care. Although their explanations varied, 7 out of 18 teachers advised that written communications should be used as the primary means for contacting students. One teacher explained, "My advice would be to encourage e-mail. Students have no patience. They will call you before they make sure they really need you... It can be never-ending." Another teacher recommended that teachers should use every free moment to make phone calls. She suggested that if a teacher is sitting at her desk waiting for a meeting to begin, she should pick up the phone and attempt to contact a student. Out of 18 teachers, 2 recommended that teachers call as early as possible when they see signs of trouble for a particular student. One teacher advised, "Don't wait... As soon as they miss one assignment, try to get them on the phone." Three teachers mentioned giving detailed feedback on assignments so students feel connected. Several teachers were asked what makes students work in response to their phone calls. Of the 18 teachers who were asked, 3 believed that making the calls personal and showing concern were the best ways to entice students to work in response to teacher phone calls. Five teachers provided follow-up data within one month of the interviews, which was considered archival data. These teachers included the results of various communication attempts, including phone calls and written communications. One teacher provided a comprehensive log detailing the results of attempted contact with 37 students over a one-week period. Another teacher sent regular updates when a student with whom she had attempted contact submitted work. Another teacher provided one-note files regarding the calls she made over a two-week period.

\section{Student Interviews}

Eleven students participated in telephone, computer, or face-to-face interviews. The re- 
sponses to interview questions were recorded as direct quotes and summaries of answers. The use of inductive analysis mandated that the codes from previous interviews be used where applicable before introducing new codes (Merriam \& Associates, 2002; Neuendorf, 2002). The codes from teacher interviews that carried over to student interviews included (d) immediate feedback, (f) prefer written communication, (h) autonomy, (j) alternate forms of communication, and (k) show concern. New categories that were added included (m) focus on larger/important assignments, (n) positive experiences, (o) reasons for not answering phone, (p) submitted requested work, and (q) explanations for work not submitted. The frequency totals for these codes are included in Table 1. Due to limited data, it was not possible to align the teacher actions from observation data with the resultant student behaviors in student interview data.

There were several comments made during both the observations and teacher interviews indicating that teachers had reason to believe that most students avoided teacher phone calls. One observation participant indicated that she believed "some of the kids will K-mail me back like 10 minutes after I have left the message... They are there but don't want to talk to you." Three teachers included comments about students who were unable to talk on the phone because they had to leave for appointments. Two teachers indicated that they have used alternate phone numbers as well as caller ID blocking in attempts to prevent students from avoiding phone calls. This aligned with the student interview data where 8 out of 11 students indicated that they do not always answer the phone when they know a teacher is calling. 
Table 1

Response Frequencies for Interviews

Data Source

Teacher interviews

Student interviews
Key Responses

Prefer written communication $\quad 24$

Students do not return calls 15

Multiple forms of communication $\quad 15$

Grades/percentages 13

Prioritize 13

Autonomy 12

Students don't want phone calls $\quad 12$

Do not expect response 10

Make it personal 7

Communication is key 8

Immediate feedback 8

Be yourself 6

Alternate communications 6

Referenced bubble students 4

Prefer written communication $\quad 11$

Submitted requested work $\quad 11$

Examples of work they would not 9

submit when requested

Liked to contact teacher by phone 9

Do not always answer the phone 8

Immediate feedback 6

Alternate forms of communication 5

Show concern 5

Focus on larger/important assignments 5

Contact teachers with questions 4

Grateful 4

Positive experiences 3

Did not like teachers calling parents 3

Reasons for not answering the phone 3

4

2

0

8

8

(n)

11

umber of 
were asked attributed the need for these repeat phone calls to the fact that the students do not tend to work in response to teacher-initiated phone calls. Of the 11 students who were interviewed, 9 indicated that there were specific assignments they would not complete even if a teacher contacted them by phone.

\section{Discussion}

Although teacher communications are vital in virtual schools (LaPointe \& Reisetter, 2008), the ways in which teachers choose to communicate vary based on the objectives of the communication. Transactional distance was not easily analyzed within the context of the results because the expectations and objectives of the various participants were not analyzed. Although the teachers in this study used personal phone calls to make contact with struggling learners in order to discover issues that may have been preventing success for these learners, the transactional distance varied within each situation. Teachers reported using K-mail and recorded phone calls much more frequently in order to address the majority of their students more quickly and to encourage students in good academic standing to maintain their academic progress.

A recent study found that virtual learners and teachers tend to prefer written communications for a variety of reasons (Watts, 2010). This information was supported by the results from most of the interview data from this study. Regular written communications and availability may be more important than teacher-initiated phone communications for virtual learners. Many students expect teachers to be available via e-mail, IM, or other digital formats for regular communications during school hours (Dennen et al., 2007; Grassian \& Kaplowitz, 2009). Out of 11 students, 8 indicated that they preferred to be K-mailed or contacted in writing by their teachers. Nine of these students held definite beliefs about when teachers should call and when they should use written forms of communication. Of the 11 students who were interviewed, 2 clearly stated that they prefer teachers not call them at all. Both of these students indicated that they would prefer written communications. Other research has indicated that students prefer communication methods that better align with the digital technology they use in their everyday personal lives (Baldarrain, 2006; Shearer, 2007; Young, Birtolo, \& McElman, 2009). These findings were reinforced by many of the students and teachers who were interviewed. Of the 11 students, 5 indicated that they liked the accessibility of their teachers who were available for instant messaging (IM). Three teachers also expressed that they had more success when they used text messaging to try and reach students. One teacher explained that she started to text message students when other teachers could not reach them. She stated, "I have really had success... They will gladly text back." This suggested that the transactional distance was not dictated by the school or location, but rather by the actions and perceptions of the students and teachers involved in the communication practices.

Observations and interviews included data which suggested that, for the most part, the students did not respond to phone calls. Five of the 18 teachers and 4 of the 11 students suggested that students do not often answer the phone when teachers call. Of the more than 60 
phone-call attempts, observed teachers spoke with only 12 students. During each observation period, the teacher called at least five students who had been contacted previously for missing assignments. Teachers did not reach any students during two of the eight observations. One teacher was able to reach 3 students with the 12 attempts she made during the observation period. The teacher notes used as archival data showed that the observed teachers, as well as other teachers, had repeatedly attempted to contact most of the students involved due to missing assignments. One teacher interview participant sent the researcher data which indicated that she had called 37 students she had previously attempted to contact via K-mail and phone calls. Fewer than $20 \%$ of those phone calls were answered. She did not receive return calls from any of the 12 families for which she left messages.

Although 8 of the 10 teacher interviews that were not associated with an observation began with the teacher sharing a success story, the overall conclusions were not altered by the interview data. All 18 teachers who were interviewed indicated that they expected very little results from their phone calls. Similarly, every teacher indicated that the number of contacts made with students compared with the number of attempts was very low. Three of these teachers agreed that "fewer than 30\%" of their phone calls resulted in actually speaking to a student. One respondent indicated that "the students who need the phone calls are going to be the ones who won't answer their phones... They are hiding." One participant indicated that he has a small group of students each year who will not respond at all to phone calls. This teacher indicated that he might make seven calls in one day to the same student in order to "try different times of day." He indicated that he was frustrated with this small portion of nonresponsive kids because he is "not able to help [any] kid if [he] can't talk to them [sic]."

This study showed that teachers did not find phone calls to be effective means of communication for learners. The results of the observations, teacher interviews, and archival documents showed some evidence of student work submitted in response to teacher-initiated phone calls. Future research on virtual school communications should include investigations regarding text messaging, instant messaging, and other social media in which teenagers often participate (Baldarrain, 2006; Shearer, 2007). 


\section{References}

Anderson, B. (2007). Independent learning. In M. Moore (Ed.), Handbook of distance education (pp. 109-122). Mahwah, NJ: Lawrence Erlbaum Associates.

Armstrong, T. (2006). The best schools. Alexandria, VA: Association for Supervision and Curriculum Development.

Baldarrain, Y. (2006). Distance education trends: Integrating new technologies to foster student interaction and collaboration. Distance Education, 27(2), 139-153.

Barbour, M., \& Reeves, T. (2009). The reality of virtual schools: A review of the literature. ScienceDirect, Computers and Education, 52(2), 402-416.

Dennen, V., Darabi, A., \& Smith, L. (2007). Instructor-learner interaction in online courses: The relative perceived importance of particular instructor actions on performance and satisfaction. Distance Education, 28(1), 65-79. doi:10.1080/01587910701305319

Ferdig, R., Cavanaugh, C., DiPietro, M., Black, E., \& Dawson, K. (2009). Virtual schooling standards and best practices for teacher education. Journal of Technology and Teacher Education, 17(4), 479-503.

Grassian, E., \& Kaplowitz, J. (Eds.). (2009). Information literacy instruction: Theory and practice $\left(2^{\text {nd }}\right.$ ed.). New York: Neal-Schuman Publishers.

Greenway, R., \& Vanourek, G. (2006). The virtual revolution: Understanding online schools. Education Next, 6(2), 34-41.

Gubrium, J., \& Holstein, J. (2001). From the individual interview to the interview society. In J. Gubrium \& J. Holstein (Eds.), Handbook of interview research: Context and method (pp. 1-32). Thousand Oaks, CA: Sage Publications.

Harms, C., Niederhauser, D., Davis, N., Roblyer, M., \& Gilbert, S. (2006). Educating educators for virtual schooling: Communicating roles and responsibilities. Electronic Journal of Communication, 16(1/2), 17-24.

Johnson, J. (2001). In-depth interviewing. In J. Gubrium \& J. Holstein (Eds.), Handbook of interview research: Context and method (pp. 103-120). Thousand Oaks, CA: Sage Publications.

Kanna, E., Gillis, L., \& Culver, C. (2009). Virtual schooling: A guide to optimizing your child's education. New York, NY: Palgrave MacMillan.

Kvale, S. (2007). Doing interviews. Los Angeles, CA: Sage Publications.

Kvale, S., \& Brinkmann, S. (2009). Interviews: Learning the craft of qualitative research interviewing ( $2^{\text {nd }}$ ed.). Los Angeles, CA: Sage Publications. 
LaPointe, L., \& Reisetter, M. (2008). Belonging online: Students' perceptions of the value and efficacy of an online learning community. International Journal on E-Learning, 7(4), 641-665. doi:1580113151

Lowry, P., Roberts, T., Romano, N., Jr., Cheney, P., \& Hightower, R. (2006). The impact of group size and social presence on small-group communication. Small Group Research, 37(6), 631-661.

Means, B., Toyama, Y., Murphy, R., Bakia, M., \& Jones, K. (2009). Evaluation of evidencebased practices in online learning: A meta-analysis and review of online learning studies. Washington, D.C.: U.S. Department of Education.

Merriam, S., \& Associates (Eds.). (2002). Qualitative research in practice: Examples for discussion and analysis. San Francisco, CA: Jossey-Bass.

Moore, M. (2007). The theory of transactional distance. In M. Moore (Ed.), Handbook of distance education (pp. 89-105). Mahwah, NJ: Lawrence Erlbaum Associates.

Moore, M., \& Kearsley, G. (1996). Distance education: A systems view. Cincinnati, OH: Wadsworth Publishing Company.

Moustakas, C. (1994). Phenomenological research methods. Thousand Oaks, CA: Sage Publications.

Neuendorf, K. (2002). The content analysis guidebook. Thousand Oaks, CA: Sage Publications.

Oliver, K., Osborne, J., \& Brady, K. (2009). What are secondary students' expectations for teachers in virtual school environments? Distance Education, 30(1), 23-45.

Patton, M. (2002). Qualitative research \& evaluation methods ( $3^{\text {rd }}$ ed.). Thousand Oaks, CA: Sage Publications.

Peterson, P. (2010). Saving schools: From Horace Mann to virtual learning. Cambridge, MA: Belknap Press.

Saba, F. (2007). A systems approach in theory building. In M. Moore (Ed.), Handbook of distance education (pp. 43-55). Mahway, NJ: Lawrence Erlbaum Associates.

Shank, G. (2006). Qualitative research: A personal skills approach ( $2^{\text {nd }}$ ed.). Columbus, $\mathrm{OH}$ : Pearson.

Shearer, R. (2007). Instructional design and the technologies: An overview. In M. Moore (Ed.), Handbook of distance education (pp. 219-232). Mahway, NJ: Lawrence Erlbaum Associates.

U.S. Department of Education. (2008). Lead and manage my school: Evaluating online 
learning: Challenges and strategies for success. Retrieved April 21, 2009, from http://www.ed.gov/admins/lead/academic/evalonline/report pg6.html\#sect6.

Watson, J. (2007). A national primer on K-12 online learning. Washington, D.C.: North American Council for Online Learning.

Watts, L. (2010). The role of dialogue in distance education: A qualitative study (Doctoral dissertation). Retrieved from ProQuest Dissertations and Theses Database. (AAT339457, ED515027).

Weiner, C. (2003). Key ingredients to online learning: Adolescent students study in cyberspace. International Journal on e-Learning, 2(3), 44-50.

Wengraf, T. (2001). Qualitative research interviewing: Biographic narrative and semistructured method. Los Angeles, CA: Sage Publications.

Yin, R. (1984). Case study research: Design and methods. Beverly Hills, CA: Sage Publications.

Yin, R. (2009). Case study research: Design and methods ( $4^{\text {th }}$ ed.). Thousand Oaks, CA: Sage Publications.

Yin, R. (2011). Qualitative research from start from finish. New York: Guilford Press.

Young, J., Birtolo, P., \& McElman, R. (2009). Virtual success: Transforming education through online learning. Learning and Leading with Technology, 36(5), 12-17. 


\section{Appendix A}

Interview Protocol-Interviews Following Teacher Observations

Thank you for taking additional time to clarify the observations and any questions I may have. I will start this interview by asking for your feedback on the observation period. I will then ask you to help clarify any gaps in my notes or to ensure the accuracy of specific notes. I will ask you a few questions regarding communication with students. Finally, I will ask you to recommend a few students with whom you communicated who may be interested in a follow-up interview with me. [Briefly summarize the purpose of the study, review IRB guidelines, and ask for consent.]

Q1. Can you share any thoughts or comments on the observation period? Please be as descriptive as you can be.

Q2. I would now like to ask you specific questions about what I just observed. [I will ask for clarification and share my initial analyses.] [I may ask for rationales for specific interactions or student work samples that relate to the observation period.]

Q3. How do you plan to follow up on these communications? [I may get specific for given observations.]

Q4. What is your rationale for how to follow up on specific phone calls?

Q5. If one of your colleagues asked you for advice on communicating with students, what might you tell him/her?

Q6. Is it OK to check back with you on [here cite specific students]?

Q7. Would you be willing to track the submissions for [here cite specific students]?

Q8. As discussed with your school administration, I would like to follow up with an interview with one or more of the students with whom you just communicated. Do you have recommendations for this process?

[Summarize the notes and ask for verification.] Thank you so much for taking the time today. I plan to analyze and summarize these notes. 


\section{Appendix B}

Interview Guide and Protocol-Interview-Only Teacher Participants

Do you have any questions about this interview or the research project?

Once we get started, I will ask you a series of questions and I will take notes on your answers. You do not have to answer any question and you may stop the interview at any time.

Q1. Can you describe a recent phone communication with a specific student or students? Please be as descriptive as possible.

Q1B. [may be needed if they describe only a limited example] Is this typical of your recent communications? Explain.

Q2. Can you provide any examples of recent communications and resultant student submissions? [may need further probes] [may use information from Q1]

Q3. What is your rationale for student communication? How do you decide whom to contact? [to be asked singularly] [may probe further on specifics from Q1 and Q2]

Q4. How do you use phone communications for students who are not struggling? How do you communicate with students who are not struggling? [These questions will be asked in one or both forms.]

Q5. What advice regarding contacting students would you give to a colleague who is new to virtual schools?

Q6. Do you have anything else you would like to share regarding student and teacher communications?

[Summarize notes and ask for verification.] Thank you so much for agreeing to this interview. I plan to analyze and summarize these notes. 


\section{Appendix C}

Interview Guide-Interview-Only Teacher Participants Needing Frequent Probes

I would like to review the informed consent and ask you to sign it. [Review the forms.]

Do you have any questions about this interview or the research project?

Once we get started, I will ask you a series of questions and I will take notes on your answers. You do not have to answer any question and you may stop the interview at any time.

Q1. I would like you to reflect on your perceptions of specific phone calls that have occurred recently. [They will be asked if they can recall a specific example or details from a recent communication incident. They will be asked if they have and are able to share any archival data to support the shared information. Specific types of data may be requested separately as needed.]

Q2. Can you provide additional support for this situation or any communication practices?

[The following will be used as needed for probes.]

Q3. Why do you call certain students?

Q4. Are there times when you use calling over e-mail or vice versa? Can you explain your rationale? Do you think the results differ? Please explain in as much detail as you can. [These will be asked singularly.]

Q5. Do students call you back if you have to leave a message? Do you provide multiple ways to contact you?

Q6. What are your expectations for student participation in and responses to phone calls?

Q6B. What do you think makes a student work in response to your phone calls? [Probe further as needed with regard to specific examples.]

Q7. Do you prefer to talk to the student or parent? Why?

Q8. What advice regarding communications with students would you give to a new virtual teacher? 


\section{Appendix D}

Supplemental Interview Guide-Students Needing Frequent Probes

I am going to ask you a series of questions in order to guide responses toward information about your recent communications with your teachers. You may ask me for clarification. You do not have to answer any question and you may stop the interview at any time.

Do you remember the last time you talked on the phone with your teacher?

Who called whom?

What was the purpose of the call?

Tell me about any work completed during the call or submitted after the call.

Do you regularly call your teachers? Can you explain that?

[depends on previous answer] Why? [do you or do you not...]

If you have a question with an assignment, what do you generally do?

How do you or your learning coach respond when a teacher calls and leaves a message?

If you could request that your teachers communicate with you when and how you prefer, what would that look like?

Do you think it is more helpful for a teacher to call you before an assignment is due or after you have missed it? Can you explain?

Do you prefer phone calls, e-mails, or K-mails?

Can you explain or describe your preferences for each type of communication? [This may need further probing or breaking down.]

Do you have any examples or samples of work that you submitted in response to a teacher phone call? [The follow-up to this question will depend on the student's response.]

Thank you for your time. Those are all of the questions I have for you today. Do you have any additional comments you would like to make about teacher phone calls or communication practices?

\section{Athabasca University $\mathbf{A}$}

